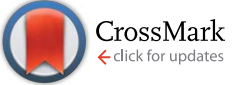

Cite this: RSC Adv., 2014, 4, 41612

\title{
Kinetics of hydrodeoxygenation of octanol over supported nickel catalysts: a mechanistic study $\dagger$
}

\begin{abstract}
Venkata Chandra Sekhar Palla, Debaprasad Shee* and Sunil K. Maity
The hydrodeoxygenation (HDO) of 1-octanol as a model aliphatic alcohol of bio-oil was investigated in a continuous down-flow fixed-bed reactor over $\gamma-\mathrm{Al}_{2} \mathrm{O}_{3}, \mathrm{SiO}_{2}$, and $\mathrm{HZSM}-5$ supported nickel catalysts in the temperature range of 488-533 $\mathrm{K}$. The supported nickel catalysts were prepared by incipient wetness impregnation method and characterized by BET, XRD, TPR, TPD, $\mathrm{H}_{2}$ pulse chemisorption, and UV-vis spectroscopy. Characterization of supported nickel (or nickel oxide) catalysts revealed existence of dispersed as well as bulk nickel (or nickel oxide) depending on the extent of nickel loading and the nature of the support. The acidity of $\gamma-\mathrm{Al}_{2} \mathrm{O}_{3}$ supported nickel catalysts decreased with increasing the nickel loading on $\gamma-\mathrm{Al}_{2} \mathrm{O}_{3}$. $n$-Heptane, $n$-octane, di-n-octyl ether, 1-octanal, isomers of heptene and octene, tetradecane, and hexadecane were identified as products of $\mathrm{HDO}$ of 1-octanol. The $\mathrm{C}_{7}$ hydrocarbons were observed as primary products for catalysts with active metal sites such as $\gamma-\mathrm{Al}_{2} \mathrm{O}_{3}$ and $\mathrm{SiO}_{2}$ supported nickel catalysts. However, $\mathrm{C}_{8}$ hydrocarbons were primarily formed over acidic catalysts such as pure HZSM-5 and HZSM-5 supported nickel catalyst. The 1-octanol conversion increased with increasing nickel loading on $\gamma-\mathrm{Al}_{2} \mathrm{O}_{3}$, and temperature and decreasing pressure and WHSV. The selectivity to products was strongly influenced by temperature, nickel loading on $\gamma-\mathrm{Al}_{2} \mathrm{O}_{3}$, pressure, and types of carrier gases (nitrogen and hydrogen). The selectivity to $\mathrm{C}_{7}$ hydrocarbons was favoured over catalysts with increased nickel loading on $\gamma-\mathrm{Al}_{2} \mathrm{O}_{3}$ at elevated temperature and lower pressure. A comprehensive reaction mechanism of $\mathrm{HDO}$ of 1-octanol was delineated based on product distribution under various process conditions over different catalysts.
\end{abstract}

Received 8th July 2014 Accepted 21st August 2014

DOI: $10.1039 / c 4 r a 06826 b$

www.rsc.org/advances

\section{Introduction}

At present our society is heavily dependent on finite fossil fuels to meet the growing demands of energy and organic chemicals. Currently, more than $80 \%$ of energy and about $90 \%$ of organic chemicals of the world are derived from fossil fuels alone. ${ }^{\mathbf{1}}$ The continuous decline of fossil fuels reserves, increase of fuel prices, and deterioration of environmental cleanliness due to large scale usage of fossil fuels have stimulated intense research worldwide to pursue carbon neutral renewable sources of energy and organic chemicals to reduce reliance on limited fossil fuels. Several renewable energies including hydro, solar, wind, geothermal, and biomass were thus developed in the past to alleviate the fossil fuel crisis. However, with the exception of biomass, all these renewable energies can only fulfil the global energy demands to some extent in the form of heat and electricity only. On the other hand, biomass, being the origin of

Department of Chemical Engineering, Indian Institute of Technology Hyderabad, Ordnance Factory Estate, Yeddumailaram 502205, Medak, Telengana, India. E-mail: dshee@iith.ac.in; Fax: +91 402301 6003; Tel: +91 4023016109

$\dagger$ Electronic supplementary information (ESI) available: HDO of 1-octanal, 1-octanol, 1-heptanol and 1-hexanol; Effects of $\mathrm{H}_{2}$ flow rate on $\mathrm{HDO}$ of 1-octanol; vapour pressure of pure components; GCMS chromatogram of liquid sample HDO of 1-octanol, 1-hexanol and 1-heptanol. See DOI: 10.1039/c4ra06826b fossil fuels, has enormous potential to deliver all forms of energy (heat, electricity, and transportation fuels) as well as basic organic chemicals in an integrated biorefinery.

Several biomass conversion technologies including gasification, fast pyrolysis, transesterification, and fermentation have thus been progressed considerably to fulfil goals of integrated biorefinery. The fast pyrolysis is one such promising technology for thermochemical conversion of world's most abundant lignocellulosic biomass directly into liquid products commonly known as bio-oil., ${ }^{2,3}$ Low capital investments and economic viability at small scale make fast pyrolysis an attractive choice for decentralized biorefinery. The bio-oil, being a mixture of more than 300 identified oxygenated hydrocarbons, could be considered as a potential feedstock for basic organic chemicals as well as transportation fuels. ${ }^{4}$ However, separation of the compounds of very low concentration from mixtures of large number of chemical compounds of many classes is practically impossible and hence bio-oil is inappropriate as feedstock for organic chemicals. The bio-oil is also unsuitable for direct usage as transportation fuels in internal combustion engines because of its high water and oxygen contents, immiscibility with petroleum fuels, low heating value $(\sim 40-45 \%$ of hydrocarbon fuels), poor storage stability due to unsaturated compounds, and high corrosiveness due to organic acids mainly acetic and 
formic acid. ${ }^{5-7}$ The removal of oxygen from bio-oils is thus indispensable for production of liquid transportation fuels.

The hydrodeoxygenation (HDO) is a propitious technology for removal of oxygen from bio-oils thereby increasing volatility and thermal stability and reducing viscosity. ${ }^{8}$ Knowledge of reaction mechanism plays crucial role for design of suitable catalysts for cost-effective HDO of bio-oils. Understanding mechanism of HDO of whole bio-oils is however highly challenging because of its diverse functionalities (phenolics, aldehydes, ketones, alcohols, organic acids, and others). The present work was therefore commenced to explore fundamental understanding of HDO of 1-octanol as a model aliphatic alcoholic functionality of bio-oil.

Enormous research efforts have been made in the past on mechanistic understanding of HDO of whole bio-oil ${ }^{2,3}$ and various oxygenated compounds of bio-oil such as phenol, anisole, guaiacol, ${ }^{9-13}$ aliphatic aldehydes like heptanal, ${ }^{\mathbf{1 4 - 1 6}}$ aromatic aldehydes like furfural, ${ }^{17,18}$ benzaldehyde, 2-phenylpropionaldehyde, cinnamaldehyde, 3-phenylpropionaldehyde, and 4-isopropylbenzaldehyde, ${ }^{\mathbf{1 6}}$ and various ketones such as 6undecanone, 2-dodecanone, 2,4-dimethyl-3-petnanone, 2,2,4,4tetramethyl-3-pentanone, ${ }^{\mathbf{1 4}}$ cyclopentanone, ${ }^{19}$ and methyl isobutyl ketone. ${ }^{20}$ However, limited information is available in open literatures on HDO of aliphatic alcohols. ${ }^{14,21-24}$ The HDO of 1-heptanol was first reported over commercial sulphided NiMo/ $\gamma-\mathrm{Al}_{2} \mathrm{O}_{3}$ and $\mathrm{CoMo} / \gamma-\mathrm{Al}_{2} \mathrm{O}_{3}$ catalysts in both flow (at $523 \mathrm{~K}$ and 15 bars of $\mathrm{H}_{2}$ ) and batch (at $523 \mathrm{~K}$ and 75 bars of $\mathrm{H}_{2}$ or $\mathrm{N}_{2}$ ) reactor using $m$-xylene or $n$-dodecane as solvent. ${ }^{21,22}$ The work was further extended in a flow reactor using two different $\mathrm{H}_{2} \mathrm{~S}$ concentration in the feed. ${ }^{23}$ Heptane and heptenes together with small quantity of diheptyl ether were observed as products. ${ }^{21-23}$ Donnis et al. reported HDO of 3-heptanol in a microscale reactor over commercial sulfided NiMo catalyst at 453 and $483 \mathrm{~K}$ and 50 bars of $\mathrm{H}_{2}$ using $n$-octane as solvent. ${ }^{13}$ Very recently, Peng et al. reported HDO of aqueous 1- and 2-propanol in a batch reactor in presence of $3 \mathrm{wt} \% \mathrm{Pt} / \mathrm{Al}_{2} \mathrm{O}_{3}$ at $473 \mathrm{~K}$ and 40 bars of $\mathrm{H}_{2}{ }^{23}$ Propane, ethane, $\mathrm{CO}_{2}$, and acetone (in case of 2propanol only) were observed as products. The HDO of 2propanol was also carried out in a fixed-bed reactor under vapor phase at different temperatures (393-523 K) using hydrogen as carrier gas.

It is quite evident from above discussion that detailed study on HDO of neat aliphatic alcohols was not attempted in the past over inexpensive nickel based catalysts to establish a comprehensive reaction mechanism. A systematic investigation was therefore commenced in the present work on HDO of 1-octanol in a fixed-bed reactor under various process conditions over several supported $\left(\gamma-\mathrm{Al}_{2} \mathrm{O}_{3}, \mathrm{SiO}_{2}\right.$, and HZSM-5) nickel catalysts with different degree of acidity to delineate a holistic reaction mechanism.

\section{Experimental}

\subsection{Catalyst preparation}

$\gamma-\mathrm{Al}_{2} \mathrm{O}_{3}$ (Alfa Aesar, 99.9\% purity), $\mathrm{SiO}_{2}$ (Aerosil-200), and HZSM-5 (Zeolyst) supported nickel catalysts were prepared by incipient wetness impregnation method using nickel nitrate hexahydrate $\left(\mathrm{Ni}\left(\mathrm{NO}_{3}\right)_{2} \cdot 6 \mathrm{H}_{2} \mathrm{O}\right.$, Merck, $>97 \%$ purity) as precursor. The nickel precursor solution was first prepared by dissolving measured amount of precursor corresponding to desired nickel loading in distilled water of volume equal to or slight excess of total pore volume of the support. The precursor solution was then added to the support and resultant mixture was agitated continuously for $2 \mathrm{~h}$ for uniform distribution of metal precursor solution into the support. The wet material was then dried overnight at $353 \mathrm{~K}$ for $12 \mathrm{~h}$. The dried material was finally calcined at $823 \mathrm{~K}$ for $6 \mathrm{~h}$. The supported nickel oxide catalysts obtained after calcination was referred as oxidized catalyst throughout the article. The $\gamma-\mathrm{Al}_{2} \mathrm{O}_{3}$ supported nickel catalysts were designated as $x \mathrm{NiAl}(x=5-20 \mathrm{wt} \%$ nickel). The HZSM-5 (Zeolyst) with $\mathrm{Si} / \mathrm{Al}$ ratio of 23 and 55 were designated as ZSM23 and ZSM55 respectively. The $15 \mathrm{wt} \%$ nickel supported on $\mathrm{SiO}_{2}, \mathrm{ZSM} 23$, and ZSM55 were represented as $15 \mathrm{NiSi}$, 15NiZSM23, and 15NiZSM55 respectively.

\subsection{Catalyst characterization}

2.2.1 Brunauer-Emmett-Teller (BET) surface area measurement. The nitrogen adsorption-desorption studies were performed in Micromeritics ASAP 2020 physisorption analyzer at liquid nitrogen temperature, $77 \mathrm{~K}$. The sample was first degassed at $473 \mathrm{~K}$ for $5 \mathrm{~h}$ under vacuum $\left(\sim 5 \times 10^{-5} \mathrm{mmHg}\right)$ to remove adsorbed moisture and other impurities present, if any. The specific surface area was determined using adsorption branch of isotherm data in the relative pressure $\left(P / P_{0}\right)$ range of 0.05 to 0.30 using multi-point BET equation. The pore volume was considered as the volume of liquid nitrogen adsorbed at $P / P_{0}=$ ca. 1 .

2.2.2 Powder X-ray diffraction (XRD). The XRD patterns of the supported nickel catalysts and pure supports were obtained in PANalytical X'Pert pro instrument in the $2 \theta$ range of 10 to $90^{\circ}$ using $\mathrm{Cu}-\mathrm{K} \alpha$ radiation $(\lambda=1.541 \AA, 45 \mathrm{kV}$, and $30 \mathrm{~mA})$ and scanning speed of $2^{\circ} \mathrm{min}^{-1}$.

2.2.3 UV-vis spectroscopy studies. The UV-vis spectra of the oxidized catalysts were acquired in PerkinElmer UV-vis NIR spectrophotometer (Model no.: Lamda 1050) equipped with Harrick scientific diffuse reflectance accessory (Praying Mantis, Model no.: DRK-4-P72) in the wavelength range of 200 to 800 $\mathrm{nm}$ using $\mathrm{BaSO}_{4}$ as reference under ambient condition.

2.2.4 Temperature programmed reduction using hydrogen ( $\mathbf{H}_{2}$-TPR). $\mathrm{H}_{2}$-TPR studies were carried out in Micromeritics AutoChem II 2920 chemisorption analyzer to understand reducibility of the oxidized catalysts. The sample was first

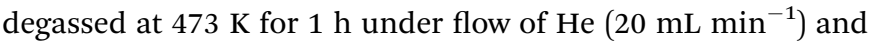
then cooled down to room temperature. Subsequently gas flow was switched over to 10 vol\% $\mathrm{H}_{2}-\mathrm{Ar}\left(50 \mathrm{~mL} \mathrm{~min}^{-1}\right)$. The sample was then heated up to $1073 \mathrm{~K}$ with a heating rate of $10 \mathrm{~K} \mathrm{~min}^{-1}$. The rate of hydrogen consumption was monitored using thermal conductivity detector (TCD). Pulse calibration studies were performed for quantification of hydrogen consumption.

2.2.5 $\mathrm{H}_{2}$ pulse chemisorption. $\mathrm{H}_{2}$ Pulse chemisorption studies were performed in a Micromeritics AutoChem II 2920 chemisorption analyzer. The oxidized catalyst was first reduced

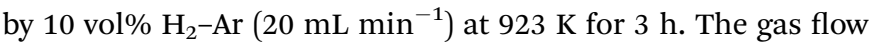


was then switched over to pure helium $\left(50 \mathrm{~mL} \mathrm{~min}^{-1}\right)$ and sample was allowed to cool down to $323 \mathrm{~K}$. The helium flow was continued for another $1 \mathrm{~h}$ to ensure complete removal of gaseous hydrogen from entire chemisorption setup and physisorbed hydrogen from catalysts surface, if any. Several pulses of measured volume of $10 \mathrm{vol} \% \mathrm{H}_{2}-\mathrm{Ar}$ gas mixture were then introduced into the reactor till three consecutive $\mathrm{H}_{2}$ peaks were similar. The hydrogen chemisorption was monitored quantitatively using a TCD detector. Metal dispersion (MD) and active metal surface area (SM) were determined based on amount of hydrogen chemisorbed.

2.2.6 Temperature programmed desorption studies using $\mathbf{N H}_{3}$ ( $\mathbf{N H}_{3}$-TPD). $\mathrm{NH}_{3}$-TPD studies were performed using Micromeritics AutoChem II 2920 chemisorption analyzer. The sample was first degassed at $473 \mathrm{~K}$ for $1 \mathrm{~h}$ under the flow of pure helium $\left(20 \mathrm{~mL} \mathrm{~min}^{-1}\right)$ to remove adsorbed moisture and other impurities present, if any. The sample was then cooled down to $373 \mathrm{~K}$. Subsequently, 10 vol\% $\mathrm{NH}_{3}-\mathrm{He}$ gas mixture $(20 \mathrm{~mL}$ $\mathrm{min}^{-1}$ ) was introduced into the reactor and continued the flow for $1 \mathrm{~h}$ to ensure complete chemisorption of ammonia. The flow of gas mixture was then switched over to pure $\mathrm{He}\left(50 \mathrm{~mL} \mathrm{~min}{ }^{-1}\right)$ and continued the flow for $1 \mathrm{~h}$ to remove physically adsorbed ammonia from the sample. The sample was consequently heated up to $1073 \mathrm{~K}$ with a heating rate of $10 \mathrm{~K} \mathrm{~min}^{-1}$ and amount of $\mathrm{NH}_{3}$ desorbed was monitored using a TCD detector. The quantity of acid sites was calculated based on amount of $\mathrm{NH}_{3}$ desorbed and pulse calibration data collected separately using same gas mixture.

\subsection{Experimental setup and procedure}

The HDO of 1-octanol was performed in an isothermally operated continuous down-flow fixed-bed reactor using either nitrogen or hydrogen as carrier gas. The known amount of oxidized catalyst diluted with appropriate quantity of quartz beads was placed inside a stainless steel tubular reactor $\left(1 / 2^{\prime \prime}\right.$ O.D. and $40 \mathrm{~cm}$ length) reinforced by quartz wool from either side. ${ }^{25}$ The reactor was then kept inside a tubular furnace consisting of two heating zones (preheating and reaction). The temperature of the reaction zone was controlled by a PID controller within $\pm 1 \mathrm{~K}$. The flow rate of all gases was controlled by individual mass flow controllers (Bronkhorst, EL-Flow). The oxidized catalysts were first reduced by hydrogen $\left(25 \mathrm{~mL} \mathrm{~min}{ }^{-1}\right)$ at $923 \mathrm{~K}$ for $3 \mathrm{~h}$. The supported nickel catalysts obtained after reduction were referred as reduced catalyst throughout the article. The reactor was then cooled down to desired reaction temperature and 1-octanol was pumped into the reactor at specified flow rate using a HPLC pump (Lab alliance, Series-I). The product gases leaving the reactor were then passed through a vertical condenser. The non-condensable gases separated in a gas-liquid separator were subsequently analyzed online by gas chromatograph (GC) equipped with TCD detector and Carbosieve-S-II packed column (Chromatopak, $3 \mathrm{~m} \times 1 / 8^{\prime \prime}$ ) using argon as carrier gas. Liquid samples were collected at regular interval of time after reaching steady state condition. The products were identified using GC attached with mass spectroscopy (Shimadzu, GCMS-QP2010 Ultra). Occurrence of the products was confirmed by comparing standard mass fragment data available with data acquisition software (Wiley and NIST standard libraries). The products were quantified by GC (Shimadzu, GC-2014) using capillary column (ZB-5HT Inferno, Phenomenex, $30 \mathrm{~m} \times 0.32 \mathrm{~mm} \times 0.10 \mu \mathrm{m})$ connected with flame ionization detector (FID). The following GC oven temperature programming was used to obtain well resolved chromatogram: Initially oven was kept at $313 \mathrm{~K}$ for 3 minutes and then temperature was increased to $493 \mathrm{~K}$ with a ramping rate of $15 \mathrm{~K} \mathrm{~min}^{-1}$, and held at this temperature for $3 \mathrm{~min}$. Injector and detector were maintained at $493 \mathrm{~K}$ and $523 \mathrm{~K}$ respectively. The material balance was checked for all experimental runs and errors were within $\pm 3 \%$.

\section{Results and discussion}

\subsection{Catalyst characterization}

The BET surface area and pore volume of the oxidized catalysts and pure supports are shown in Table 1 . The surface area of the

Table 1 Physico-chemical properties of supported nickel catalysts and pure supports ${ }^{a}$

\begin{tabular}{|c|c|c|c|c|c|c|c|c|}
\hline \multirow[b]{2}{*}{ Catalyst } & \multirow[b]{2}{*}{$S^{\mathrm{a}}$} & \multirow[b]{2}{*}{$\mathrm{PV}^{\mathrm{a}}$} & \multirow[b]{2}{*}{$\mathrm{MD}^{\mathrm{b}}$} & \multirow[b]{2}{*}{$\mathrm{SM}^{\mathrm{b}}$} & \multirow[b]{2}{*}{$\mathrm{MH}_{2}{ }^{\mathrm{a}}$} & \multirow[b]{2}{*}{$\mathrm{MNH}_{3}{ }^{\mathrm{b}}$} & \multicolumn{2}{|c|}{ Particle size $^{\mathrm{c}}, \mathrm{nm}$} \\
\hline & & & & & & & Oxidized & Reduced \\
\hline $\mathrm{Al}_{2} \mathrm{O}_{3}$ & 104 & 8.1 & - & - & & 0.35 & - & - \\
\hline $5 \mathrm{NiAl}$ & 88 & 8.3 & 0.21 & 1.42 & 0.54 & 0.23 & - & - \\
\hline 10NiAl & 78 & 8.0 & 0.36 & 2.43 & 2.06 & 0.21 & 9.0 & 9.0 \\
\hline $15 \mathrm{NiAl}$ & 68 & 7.9 & 0.15 & 0.98 & 2.91 & 0.17 & 22.0 & 29.0 \\
\hline 20NiAl & 69 & 7.7 & 0.16 & 1.09 & 3.83 & 0.17 & 31.8 & 36.0 \\
\hline $\mathrm{SiO}_{2}$ & 209 & - & - & - & - & - & - & - \\
\hline $15 \mathrm{NiSi}$ & 164 & - & 0.29 & 1.96 & 1.93 & - & 19.1 & 26.2 \\
\hline ZSM23 & 318 & - & - & - & - & 1.09 & - & - \\
\hline ZSM55 & 370 & - & - & - & - & 0.64 & - & - \\
\hline 15NiZSM23 & 232 & - & 0.18 & 1.21 & 1.83 & 0.90 & 23.9 & 28.8 \\
\hline 15NiZSM55 & 310 & - & 0.37 & 2.48 & 1.91 & 0.46 & 20.5 & 26.2 \\
\hline
\end{tabular}

${ }^{a} S=$ surface area, $\mathrm{m}^{2} \mathrm{~g}^{-1} ; \mathrm{PV}=$ pore volume, $\mathrm{mL} \mathrm{g}^{-1} ; \mathrm{MD}=$ metal dispersion, $\%$; $\mathrm{SM}=$ metallic surface area, $\mathrm{m}^{2} \mathrm{~g}^{-1} ; \mathrm{MH}_{2}=$ total amount of $\mathrm{H}_{2}$ consumed mmol g ${ }^{-1}$ of cat.; $\mathrm{MNH}_{3}=$ total amount of $\mathrm{NH}_{3}$ desorbed, mmol g ${ }^{-1}$. ${ }^{\text {a }}$ Oxidized catalysts. ${ }^{\mathrm{b}}$ Reduced catalyst. ${ }^{\mathrm{c}}$ Calculated using DebyeScherer equation. 
oxidized catalysts was somewhat lesser than pure supports. The decrease of surface area might be due to blocking of pores and difference in atomic weight of nickel and supports. Furthermore, surface area of oxidized catalysts was observed to decrease with increasing nickel loading up to $15 \mathrm{wt} \%$ on $\gamma-\mathrm{Al}_{2} \mathrm{O}_{3}$ and levelled off thereafter. The pore volume was also decreased slightly with increasing nickel loading. MD and SM determined from $\mathrm{H}_{2}$ chemisorption results was increased with increasing nickel loading till $10 \mathrm{wt} \%$ and levelled off thereafter.

The XRD patterns of both oxidized and reduced catalysts and pure supports are shown in Fig. 1A and B respectively. Analysis of XRD patterns of oxidized and reduced $x \mathrm{NiAl}$ catalysts confirmed presence of bulk nickel oxide (PDF\#780643) and nickel (PDF \#882326) respectively with nickel loading of $10 \mathrm{wt} \%$ or more on $\gamma-\mathrm{Al}_{2} \mathrm{O}_{3}{ }^{26}$ It was further observed that intensity of bulk nickel oxide (or nickel) peaks was increased with increasing nickel loading on $\gamma-\mathrm{Al}_{2} \mathrm{O}_{3}$. However, only dispersed nickel oxide (or nickel) was present in $x \mathrm{NiAl}$ with nickel loading below $10 \mathrm{wt} \%$. XRD patterns of 15NiSi, 15NiZSM23, and 15NiZSM55 also revealed presence of bulk nickel oxide and
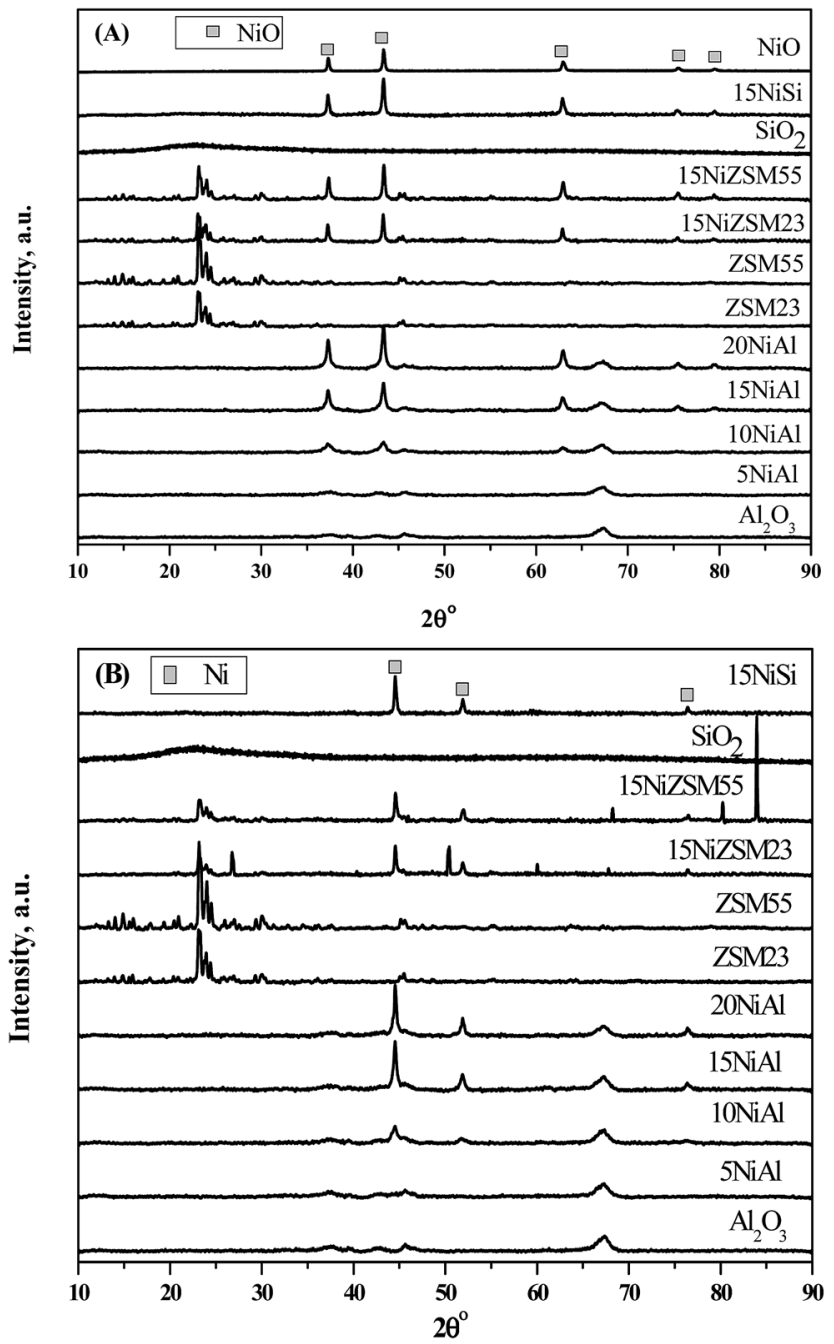

Fig. 1 XRD patterns of (A) oxidized and (B) reduced $\gamma-\mathrm{Al}_{2} \mathrm{O}_{3}, \mathrm{SiO}_{2}$ ZSM23, and ZSM55 supported nickel catalysts.

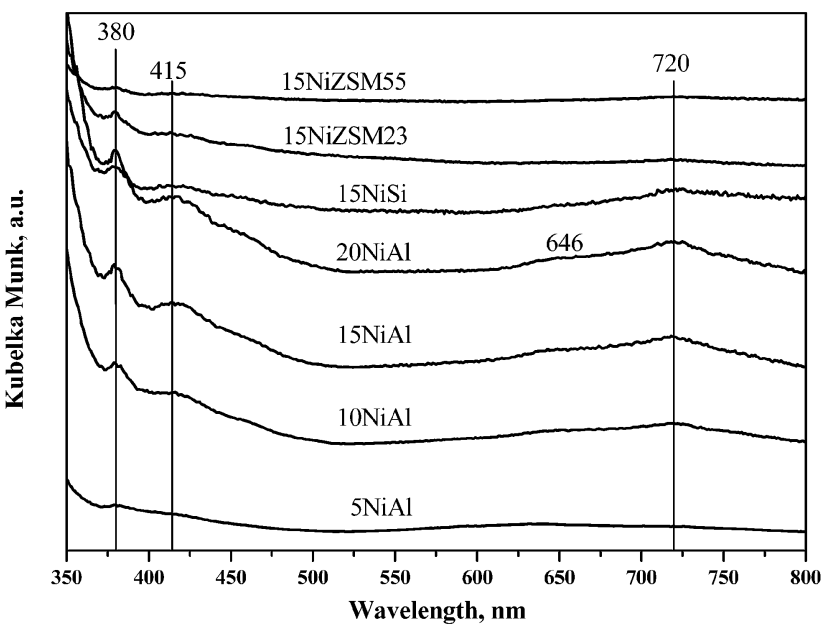

Fig. 2 UV-vis spectra of oxidized $x \mathrm{NiAl}, 15 \mathrm{NiSi}, 15 \mathrm{NiZSM} 23$, and 15 NiZSM55 catalysts.

nickel in oxidized and reduced catalysts respectively. From these results it may be concluded that characteristic bulk nickel peak appeared in XRD pattern of reduced catalysts were most likely originated by reduction of bulk nickel oxide present in the oxidized catalysts. Particle size of the reduced and oxidized catalysts was determined using Debye-Scherer equation. The size of nickel oxide or nickel depends on the nickel loading and nature of support. In case of $x$ NiAl catalysts, the particle size was observed to increase with increasing nickel loading.

The UV-vis DRS spectra of the oxidized catalysts under ambient condition are shown in Fig. 2. The spectra at lower wavelength region are however not shown due to presence of strong charge transfer band that gives very high value of Kubelka Munk function. The band appeared at 280-320 nm (not shown in Fig. 2) for all catalysts is attributed to $\mathrm{O}^{2-} \rightarrow \mathrm{Ni}^{+2}$ charge transfer. ${ }^{27}$ For $x$ NiAl catalysts, position of this band shifted to higher wavelength with increasing nickel loading. It may be due to increased concentration of bulk nickel oxide. Additional band appeared for $x \mathrm{NiAl}$ at 380 and $646 \mathrm{~nm}$ are characteristics of nickel aluminate $\left(\mathrm{NiAlO}_{4}\right)$ which is a solid solution of nickel oxide and $\gamma-\mathrm{Al}_{2} \mathrm{O}_{3} .{ }^{27}$ Evolution of DRS bands at 380,415 and $715-720 \mathrm{~nm}$ was due to bulk nickel oxide with octahedral geometry. ${ }^{27}$ For $x \mathrm{NiAl}$, these bands were observed for $10 \mathrm{wt} \%$ and more nickel loading on $\gamma-\mathrm{Al}_{2} \mathrm{O}_{3}$.

TPR results of the oxidized catalysts are shown in Fig. 3. The peak appeared at $699 \mathrm{~K}$ for $x \mathrm{NiAl}$ was due to reduction of dispersed nickel oxide possessing strong interaction with the support. ${ }^{26}$ The peak observed at $627-650 \mathrm{~K}$ for $15 \mathrm{NiAl}$ and $20 \mathrm{NiAl}$ was due to reduction of bulk nickel oxide possessing no or little interaction with support. ${ }^{26}$ TPR profile of bulk nickel oxide further confirms above argument as shown in the same figure. Moreover, intensity of the reduction peaks corresponding to both dispersed and bulk nickel oxide was increased with increasing nickel loading on $\gamma-\mathrm{Al}_{2} \mathrm{O}_{3}$. The XRD and UV-vis spectroscopy results also confirmed presence of bulk as well as dispersed nickel oxide for $15 \mathrm{NiAl}$ and $20 \mathrm{NiAl}$. However, for $10 \mathrm{NiAl}$, the reduction peak corresponding to bulk nickel oxide 


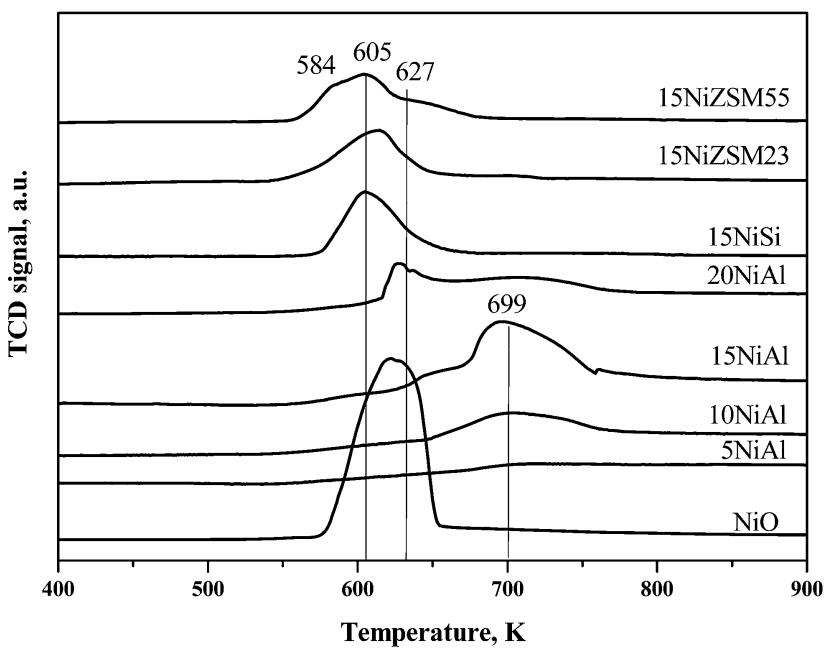

Fig. 3 TPR profiles of oxidized $x \mathrm{NiAl}, 15 \mathrm{NiSi}, 15 \mathrm{NiZSM} 23$, and 15NiZSM55 catalysts.

was appeared as weak shoulder in TPR profiles though it was very prominent in XRD pattern and UV-vis spectra. This might be due to either presence of insignificant amount of bulk nickel oxide in 10NiAl or TPR studies are less sensitive compared to XRD and UV-vis spectroscopy for the detection of specifically small amount of bulk NiO species. The oxidized 15ZSM23 and 15ZSM55 also showed characteristic reduction peaks of both bulk and dispersed nickel oxide. In contrast, 15NiSi showed only a broad reduction peak centered at $605 \mathrm{~K}$. The XRD pattern and UV-vis spectroscopy confirmed presence of bulk nickel oxide in $15 \mathrm{NiSi}$. Thus it can be concluded that reduction of different surface nickel oxide species in 15NiSi might happen within a small range of temperature giving rise to a broad reduction peak centred at $605 \mathrm{~K}$. The $\mathrm{H}_{2}$ consumption during TPR studies was calculated (Table 1 ) and values were matched closely with theoretical amounts of $\mathrm{H}_{2}$ required to reduce nickel oxide for $x$ NiAl catalysts. Thus, these results indicate that only nickel oxides (dispersed and bulk) are present in the supported nickel catalysts. Contrary to $x \mathrm{NiAl}, \mathrm{H}_{2}$ consumption values for $15 \mathrm{NiSi}, 15 \mathrm{NiZSM} 23$, and 15NiZSM55 were lower than theoretically required amounts thereby suggesting the presence of differently coordinated nickel species or a fraction of the nickel may not be accessible to hydrogen during reduction.

$\mathrm{NH}_{3}$-TPD results of reduced catalysts and pure supports are shown in Fig. 4 and Table 1. Pure $\gamma-\mathrm{Al}_{2} \mathrm{O}_{3}$ showed a distinct ammonia desorption peak at $445 \mathrm{~K}$ corresponding to weak/or moderate acid sites. ${ }^{26}$ The intensity of this peak was suppressed gradually with increasing nickel loading indicating reduction of acidity with increasing nickel loading on $\gamma-\mathrm{Al}_{2} \mathrm{O}_{3}{ }^{26}$ The ammonia desorption peak appeared at $913 \mathrm{~K}$ and above may be due to dehydroxylation of hydroxyl group present in $\gamma$ $\mathrm{Al}_{2} \mathrm{O}_{3}$. For zeolites, strength and number of acid sites were significantly more compared to pure $\gamma-\mathrm{Al}_{2} \mathrm{O}_{3}$ with characteristic ammonia desorption peaks at $445-461 \mathrm{~K}$ and $645-657 \mathrm{~K}$. The intensity of these peaks was enhanced with decreasing $\mathrm{Si} / \mathrm{Al}$ ratio suggesting increase of number of acid sites with

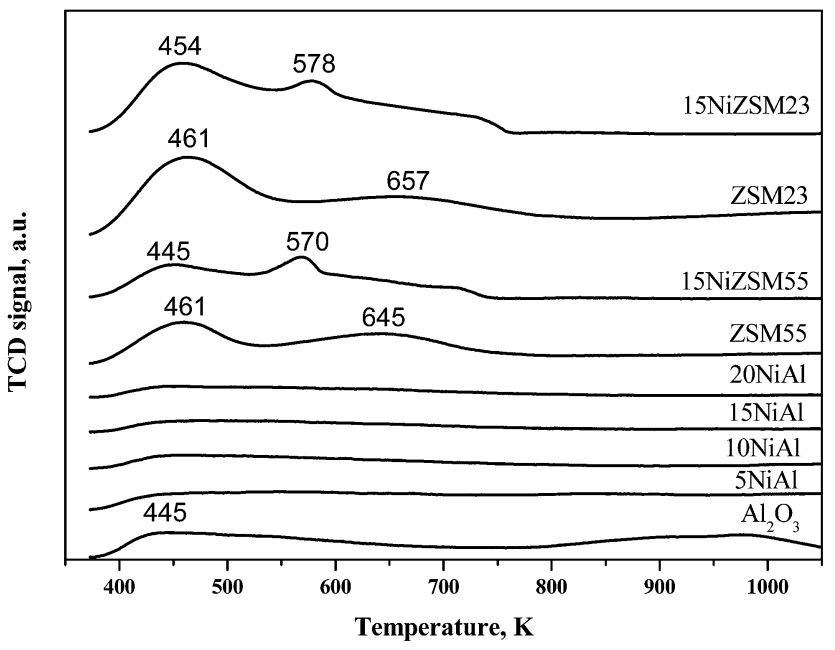

Fig. $4 \mathrm{NH}_{3}$-TPD profiles of $x \mathrm{NiAl}, 15 \mathrm{NiSi}, 15 \mathrm{NiZSM} 23,15 \mathrm{NiZSM} 55$ catalysts, and pure supports.

decreasing Si/Al ratio. Upon deposition of nickel on HZSM-5, intensity of the peaks was decreased significantly together with shifting of peaks to lower temperature (570-578 K). These results indicate that strength and number of acid sites decrease on deposition of nickel on zeolites.

\subsection{Reaction mechanism}

The $n$-heptane, $n$-octane, isomers of heptene (heptenes) and octene (octenes), 1-octanal, di- $n$-octyl ether (DOE), tetradecane (TETD), and hexadecane (HEXD) were identified by GC-MS in the liquid samples for HDO of 1-octanol (Fig. S1†). Small quantities of octanoic acid (OA) and octyl caprylate (OC, octyl octanoate, $\left.\mathrm{C}_{7} \mathrm{H}_{15} \mathrm{COOC}_{8} \mathrm{H}_{17}\right)$ were also identified in few cases. Furthermore, liquid samples were found to undergo phase separation (aqueous and organic) especially at high conversion of 1-octanol (or freezing the samples below $273 \mathrm{~K}$ ) demonstrating formation of water as one of the product. A comprehensive reaction mechanism of HDO of 1-octanol was delineated based on products distribution as shown in Scheme 1. 1-Octanol undergoes HDO following two different routes on two different sites of the catalyst: acid and metal.

In the first route, 1-octanol undergoes dehydration to octenes either directly or through intermediate etherification reaction via DOE with elimination of one mole of water in each step. The octenes subsequently undergo either hydrogenation to $n$-octane or oligomerization followed by hydrogenation to HEXD. The acidic sites of catalysts might be responsible for etherification, dehydration, and oligomerization reactions. DOE, $n$-octane, and octenes were major products for highly acidic pure HZSM-5 and HZSM-5 supported nickel catalysts and their selectivity were also increased with increasing acidity of the catalysts thereby justifying above statements. The dehydration of alcohols, for example ethanol and butanol, was reported previously over acidic catalysts in the temperature range of $498-748 \mathrm{~K}^{28}$ The oligomerization of olefins, for instance 1-hexene and 1-octene, was also described over various 


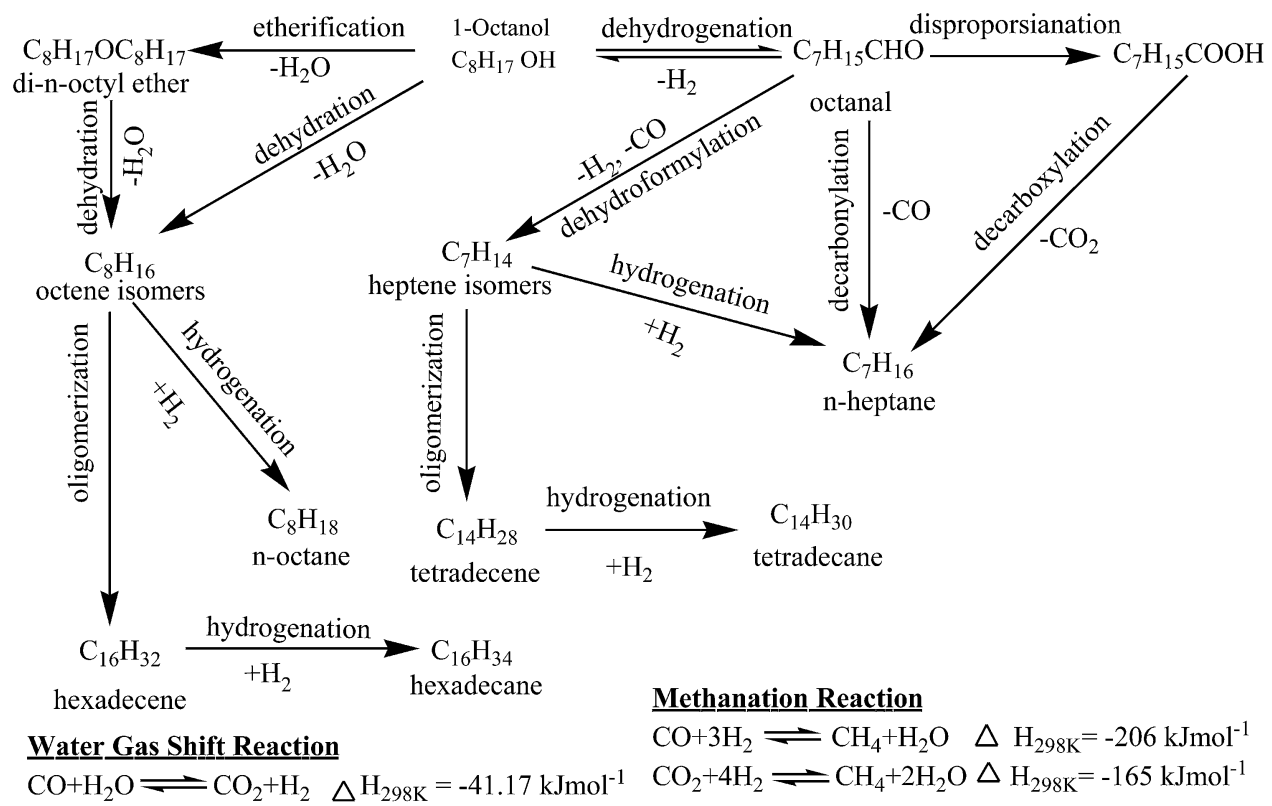

Scheme 1 Reaction mechanism for HDO of 1-octanol.

solid acid catalysts such as solid phosphoric acid, ZSM-5, zeolite-Y, and cation exchange resins..$^{29,30}$ For HDO of 1-heptanol using sulphided $\mathrm{NiMo} / \gamma-\mathrm{Al}_{2} \mathrm{O}_{3}$ and $\mathrm{CoMo} / \gamma-\mathrm{Al}_{2} \mathrm{O}_{3}$ catalysts, dehydration of alcohol to alkene followed by its hydrogenation to alkane were reported too. ${ }^{21-23}$

Following second route, 1-octanol undergoes dehydrogenation reaction over active metal sites of the catalysts leading to formation of 1-octanal. The 1-octanal is consequently converted to either $n$-heptane by decarbonylation reaction or heptenes by dehydroformylation reaction. The heptenes are then either hydrogenated to $n$-heptane or oligomerized followed by hydrogenated to TETD. The GC analysis of gas sample under nitrogen as carrier gas additionally confirmed formation of both hydrogen and carbon monoxide thereby justifying above claim. Moreover, 1-octanal, $n$-heptane, and heptenes were primary products for $\gamma-\mathrm{Al}_{2} \mathrm{O}_{3}$ supported nickel catalysts as discussed in subsequent section. Furthermore, their combined selectivity was observed to increase with increasing nickel loading on $\gamma$ $\mathrm{Al}_{2} \mathrm{O}_{3}$ demonstrating role of metal sites for dehydrogenation, decarbonylation, and dehydroformylation reactions. For catalytic $\mathrm{HDO}$ of $\mathrm{C}_{3}$ alcohols, Peng et al. also suggested that alcohol was first dehydrogenated to aldehyde over metal sites. ${ }^{24}$ The CO underwent water gas shift reaction to give $\mathrm{CO}_{2}$ and $\mathrm{H}_{2}$.

To confirm proposed pathways of conversion of 1-octanal to various products, an independent experiment of HDO of 1-octanal was performed over $15 \mathrm{NiAl}$ catalyst using hydrogen as carrier gas (Table $\mathrm{S} 1 \dagger$ ). In this particular experiment, $n$ heptane, 1-octanol, and heptenes were identified as major products together with small amounts of DOE, n-octane, octenes, HEXD, TETD, and OA. The formation of 1-octanol suggests that dehydrogenation of 1-octanol to 1-octanal is a reversible reaction. Small amount of $\mathrm{CO}_{2}$ and $\mathrm{CH}_{4}$ were also detected for HDO of 1-octanol under hydrogen as carrier gas. Formation of $\mathrm{CO}_{2}$ and $\mathrm{CH}_{4}$ may be due to water gas shift reaction and methanation of $\mathrm{CO} / \mathrm{CO}_{2}$ respectively as shown in Scheme 1. Formation of OA was however not well understood and might be formed by disproportionation of 1-octanal. The OA formed further undergoes esterification reaction with 1octanol producing OC. The reaction mechanism is generally confirmed directly through in situ or operando spectroscopic studies. However, it is beyond the scope of present study and left to the researchers as an open challenge problem for future study.

In order to demonstrate the proposed mechanism as generalized one, study was further extended to HDO of 1-heptanol and 1-hexanol over $15 \mathrm{NiAl}$ at $518 \mathrm{~K}$. The products distributions for both alcohols were fully in line with proposed mechanism thereby validating the proposed mechanism (Table S1, Fig S2 and S3 $\dagger$ ). All subsequent studies were performed with 1-octanol only.

$$
\left(\begin{array}{l}
\text { Selectivity to } n \text {-heptane } \\
\text { heptenes, } n \text {-octane, octenes } \\
\text { octanal, or octanoic acid }
\end{array}\right), \%=100 \times \frac{\left(\begin{array}{l}
\text { Rate of moles of } n \text {-heptane, heptenes, } \\
n \text {-octane, octenes, 1-octanal, } \\
\text { or octanoic acid formed }
\end{array}\right.}{\text { Rate of moles of 1-octanol reacted }}
$$




\subsection{Reaction studies}

The HDO of 1-octanol was investigated in a down-flow fixed-bed reactor over $\gamma-\mathrm{Al}_{2} \mathrm{O}_{3}, \mathrm{SiO}_{2}, \mathrm{ZSM} 23$, and ZSM55 supported nickel catalysts using either nitrogen or hydrogen as carrier gas under wide range of pressures (1-10 bars), nickel loadings on $\gamma-\mathrm{Al}_{2} \mathrm{O}_{3}$ (0-20 wt\%), weight hourly space velocities (WHSV) (2.5-9.99 $\mathrm{h}^{-1}$ ), and temperatures (488-530 K). $n$-Heptane, heptenes, 1octanal, DOE, $n$-octane, and octenes were identified as primary products of HDO of 1-octanol in presence of both nitrogen and hydrogen as carrier gas. The TETD, HEXD, OA, and OC were obtained as minor products of the reaction. The selectivity to $n$ heptane, heptenes, $n$-octane, octenes, 1-octanal, and OA used throughout the article is defined by eqn (1). The selectivity to DOE, TETD, HEXD, and OC is defined by eqn (2). It may be noted that all isomers of heptene (1-heptene, 2-heptene, and 3heptene) and octene (1-octene, 2-octene, and 3-octene) are included within the selectivity to heptenes and octenes respectively.

3.3.1 Effects of carrier gases. In order to capture effects of carrier gas on conversion of 1-octanol and selectivity to various products, two independent experiments were conducted using nitrogen and hydrogen as carrier gas over $15 \mathrm{NiAl}$ catalyst. The conversion of 1-octanol was observed to be considerably higher for hydrogen as carrier gas compared to that of nitrogen (Table $\mathrm{S} 2 \dagger)$. It may be due to the fact that hydrogenation of intermediate alkenes drives the reactions in forward direction leading to higher conversion of 1-octanol under hydrogen as carrier gas. The selectivity to alkanes ( $n$-heptane and $n$-octane) was higher for hydrogen as carrier gas. The selectivity to alkenes (heptenes and octenes), oligomer products (TETD and HEXD), and 1octanal were however higher for nitrogen as carrier gas. For the reaction with hydrogen as carrier gas, the intermediate alkenes undergo hydrogenation preferentially to alkanes under the reaction conditions resulting in higher selectivity to alkanes. For reaction with nitrogen as carrier gas, the alkenes however can only undertake oligomerization route leading to higher selectivity to TETD and HEXD. The reversible dehydrogenation of 1-octanol to 1-octanal is also favourable under nitrogen as carrier gas leading to higher selectivity of 1-octanal. Good amount of alkanes were also formed under nitrogen as carrier gas. The dehydrogenation of 1-octanol to 1-octanal is the source of hydrogen for hydrogenation of intermediate alkenes. Since higher conversion of 1-octanol was observed for hydrogen as a carrier gas; further studies were carried out using hydrogen as carrier gas.

In order to determine critical flow rate of hydrogen, two independent experiments were conducted for two different hydrogen flow rates (20 and $40 \mathrm{~mL} \mathrm{~min}^{-1}$ ) maintaining 1octanol flow rates and WHSV constant. However, 1-octanol conversion and selectivity to products remained practically unaffected with increasing hydrogen flow rate (Table S3†). Therefore, all subsequent experiments were carried out with 20 $\mathrm{mL} \min ^{-1}$ of hydrogen flow rate.

3.3.2 Catalyst stability study. The stability of supported nickel catalysts was tested for HDO of 1-octanol over $15 \mathrm{NiAl}$ catalyst. The conversion of 1-octanol was calculated based on collected reaction data at different time-on-stream (TOS) up to $600 \mathrm{~min}$ to know the variation of catalytic activity with TOS as shown in Fig. 5. As observed from figure, the catalyst was highly active initially and catalytic activity was decreased gradually with increasing TOS. After about $240 \mathrm{~min}$ of TOS, variation of conversion of 1-octanol was however found to be insignificant ( $\sim 0.7 \%$ variation) with TOS up to $600 \mathrm{~min}$. Moreover, the variation of selectivity of major products was also insignificant after $240 \mathrm{~min}$ of TOS. From this result it can be safely concluded that the catalyst is quite stable after about $240 \mathrm{~min}$ of TOS. Hence, conversion and selectivity calculations for all experimental runs were performed after reaching steady state conditions.

3.3.3 Effects of pressure. The investigation of effects of pressure is very much important to understand performance of HDO of 1-octanol under two different phases (vapor and liquid). The vapor pressure of 1-octanol and products of HDO of 1octanol were calculated at several operating temperatures using

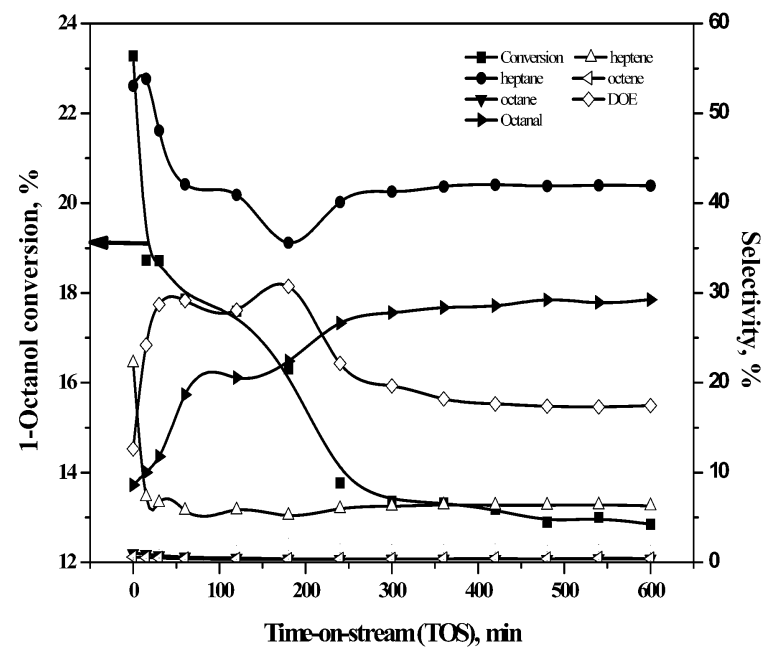

Fig. 5 Variation of activity and selectivity of major products for HDO of 1-octanol with TOS. Reaction conditions: catalyst $=15 \mathrm{NiAl}$, temperature $=488 \mathrm{~K}$, pressure $=1$ bar, $\mathrm{WHSV}=3.99 \mathrm{~h}^{-1}$. 
Table 2 Effects of pressure on HDO of 1-octanol ${ }^{a}$

\begin{tabular}{|c|c|c|c|c|c|c|c|c|c|c|c|}
\hline Pressure, bar & $\begin{array}{l}\text { Conversion of } \\
\text { 1-octanol, \% }\end{array}$ & \multicolumn{10}{|c|}{ Selectivity, \% } \\
\hline 5 & 17.5 & 24.8 & 1.7 & 1.2 & 0.3 & 6.7 & 61.1 & 0.2 & 0.7 & 2.4 & 0.9 \\
\hline 10 & 7.5 & 11.2 & 0.4 & 2.6 & 0.6 & 5.4 & 65.6 & 2.6 & 5.1 & 4.2 & 2.3 \\
\hline
\end{tabular}

${ }^{a}$ Reaction conditions: temperature $=503 \mathrm{~K}$, catalyst $=15 \mathrm{NiAl}, \mathrm{WHSV}=3.99 \mathrm{~h}^{-1}$, TOS $=240 \mathrm{~min}$.

Table 3 Effects of temperature on HDO of 1-octanol ${ }^{a}$

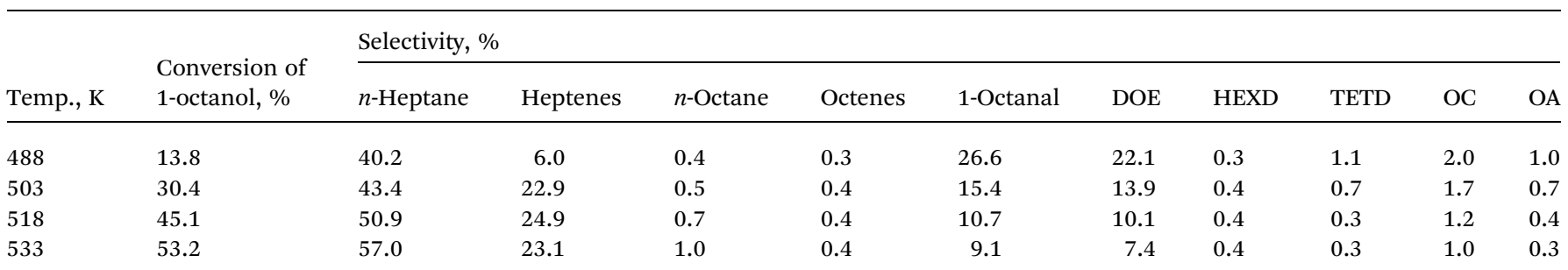

${ }^{a}$ Reaction conditions: pressure $=1$ bar, catalyst $=15 \mathrm{NiAl}, \mathrm{WHSV}=3.99 \mathrm{~h}^{-1}$, TOS $=240 \mathrm{~min}$.

Table 4 Effects of nickel loading on $\mathrm{Al}_{2} \mathrm{O}_{3}$ on $\mathrm{HDO}$ of 1 -octanol ${ }^{a}$

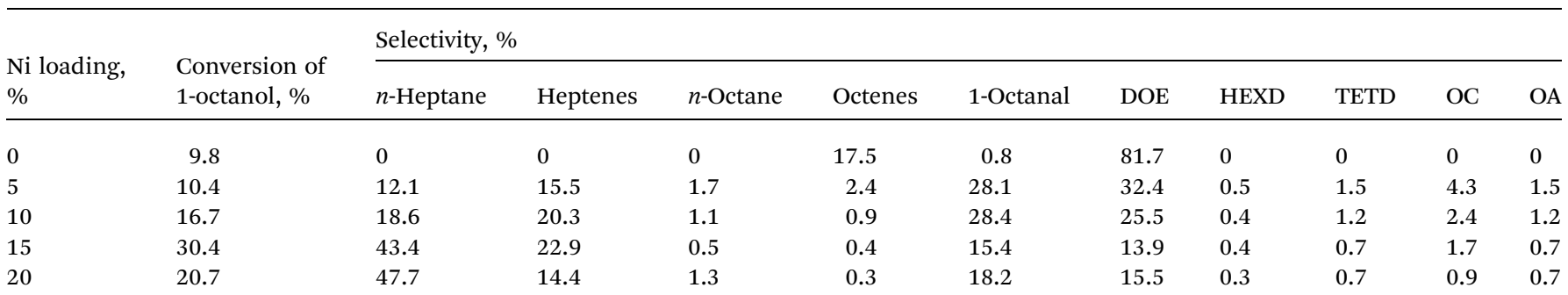

${ }^{a}$ Reaction conditions: temperature $=503 \mathrm{~K}$, pressure $=1 \mathrm{bar}, \mathrm{WHSV}=3.99 \mathrm{~h}^{-1}$, TOS $=240 \mathrm{~min}$.

Table 5 Effects of supports on HDO of 1-octanol ${ }^{a}$

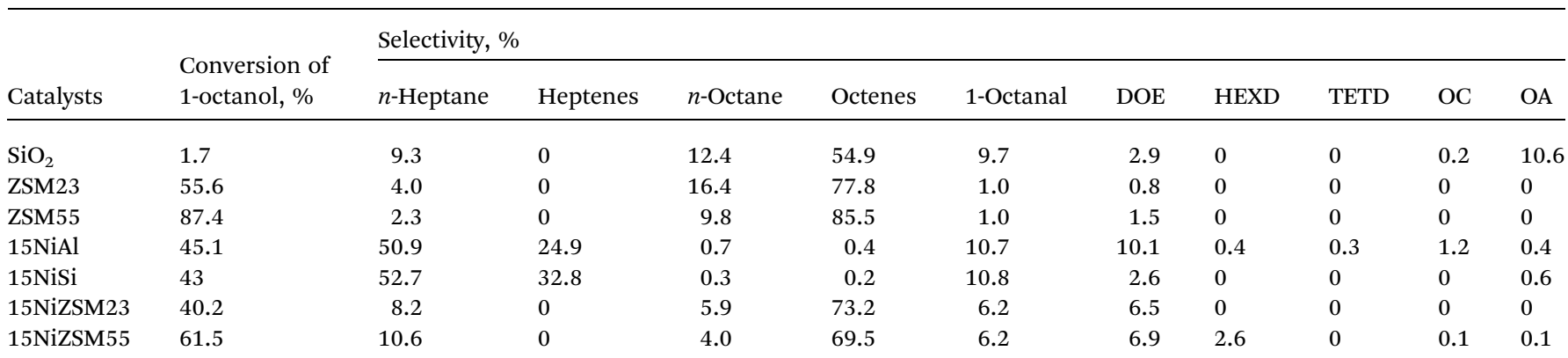

${ }^{a}$ Reaction conditions: temperature $=518 \mathrm{~K}$, pressure $=1 \mathrm{bar}, \mathrm{WHSV}=3.99 \mathrm{~h}^{-1}$, TOS $=240 \mathrm{~min}$.

Aspen Plus ${ }^{\circledR}$, Aspen Tech ${ }^{\mathrm{TM}}$ software as presented in Table S4. $\dagger$ 1-Octanol remains in vapor phase at atmospheric pressure under the range of operating temperatures as observed from the table. At 3.30 bars and above, 1-octanol transformed to liquid phase at the maximum operating temperature of $518 \mathrm{~K}$. On the other hand, $\mathrm{C}_{7}$ and $\mathrm{C}_{8}$ hydrocarbon products require high pressure to persist in liquid phase. DOE, TETD, and HEXD however remain in liquid phase even at atmospheric pressure for entire range of working temperatures.

The HDO of 1-octanol was accordingly designed at three different pressures, 1, 5, and 10 bars as presented in Table 2. The conversion of 1-octanol was decreased with increasing pressure indicating that reaction was unfavourable at higher pressure. With increasing pressure, selectivity to 1-octanal, $n$ - 
Table 6 Effects of WHSV on HDO of 1-octanol ${ }^{a}$

\begin{tabular}{lllllllllll}
\hline \multicolumn{1}{l}{ Conversion of } \\
WHSV,
\end{tabular}

${ }^{a}$ Reaction conditions: temperature $=503 \mathrm{~K}$, pressure $=1$ bar, catalyst $=15 \mathrm{NiAl}$, TOS $=240 \mathrm{~min}$.

heptane, and heptenes were decreased; while selectivity to DOE, $n$-octane, octenes, TETD, and HEXD were increased. According to Le Chatelier's principle, vapor phase reactions with positive change in number of moles such as dehydrogenation, dehydroformylation, decarbonylation are unfavourable at high pressures and vice versa. This leads to lower selectivity to 1octanal, $n$-heptane, and heptenes at higher pressure. The etherification and oligomerization reactions are however favourable at high pressures leading to increasing trends of selectivity to $n$-octane, octenes, DOE, TETD, and HEXD with pressures. All subsequent experiments were carried out under vapor phase at atmospheric pressure.

3.3.4 Effects of temperature. HDO of 1-octanol was studied at four different temperatures, $488,503,518$, and $533 \mathrm{~K}$ as shown in Table 3. As observed from the table, 1-octanol conversion was increased with increasing temperature as expected. The combined selectivity to $n$-heptane, heptenes, and 1-octanal were increased with increasing temperatures. From these results it may be concluded that higher temperature favors dehydrogenation of 1-octanol to 1-octanal more than dehydration of 1-octanol to DOE and octenes. However, selectivity to 1-octanal was decreased with increasing temperature. These results clearly show that increase of rate of dehydroformylation and decarbonylation of 1-octanal with temperature is much more than dehydrogenation of 1-octanol to 1octanal. The variation of selectivity to oligomerized products, HEXD and TETD was remained insignificant with increasing reaction temperature.

3.3.5 Effects of nickel loading and supports. The nickel loading on $\gamma-\mathrm{Al}_{2} \mathrm{O}_{3}$ were varied from 0 to $20 \mathrm{wt} \%$. The results of nickel loading on $\gamma-\mathrm{Al}_{2} \mathrm{O}_{3}$ on conversion of 1-octanol and selectivity to products are shown in Table 4 . As observed from table, 1-octanol conversion were increased with increasing nickel loading on $\gamma-\mathrm{Al}_{2} \mathrm{O}_{3}$ up to $15 \mathrm{wt} \%$ and levelled off thereafter. Therefore, $15 \mathrm{wt} \%$ nickel loading on $\gamma-\mathrm{Al}_{2} \mathrm{O}_{3}$ was deliberated as critical nickel loading and henceforth all subsequent experiments were conducted using $15 \mathrm{wt} \%$ nickel loading on $\gamma$ $\mathrm{Al}_{2} \mathrm{O}_{3}$. The increase of nickel loadings on $\gamma-\mathrm{Al}_{2} \mathrm{O}_{3}$ has significant impacts on selectivity to products. The selectivity to $n$-octane, octenes, and DOE were decreased with increasing nickel loading on $\gamma-\mathrm{Al}_{2} \mathrm{O}_{3}$. This may be due to decrease of acidity of the catalysts with increasing nickel loading on $\gamma-\mathrm{Al}_{2} \mathrm{O}_{3}$ as observed from ammonia TPD (Table 1). With increasing nickel loading on $\gamma-\mathrm{Al}_{2} \mathrm{O}_{3}$, the combined selectivity to 1 -octanal, $n$-heptane, and heptenes was increased due to increase of nickel contents (responsible for hydrogenation/dehydrogenation and decarbonylation) in the catalyst.

In order to delineate role of supports on the reaction, $\mathrm{HDO}$ of 1-octanol was conducted over pure supports $\left(\gamma-\mathrm{Al}_{2} \mathrm{O}_{3}, \mathrm{SiO}_{2}\right.$, ZSM23 and ZSM55) as well (Tables 4 and 5). 1-Octanol mainly undergoes dehydration and etherification reaction in presence of pure supports resulting in formation of $n$-octane, octenes, and DOE as foremost products together with only small quantity of 1-octanal. The relative proportion of dehydration and etherification products strongly depends on strength and nature of acid sites (Lewis and Bronstead). Strongly acidic supports promote dehydration of alcohols resulting in the formation of corresponding olefins as major products. In general, Lewis acid sites of $\gamma-\mathrm{Al}_{2} \mathrm{O}_{3}$ are responsible for etherification reaction of 1-octanol yielding DOE as major product together with lesser amount of octenes. The octenes thus formed however cannot easily undergo hydrogenation reaction even in presence of hydrogen due to non-availability of active metal sites in the catalyst. Hence, poor selectivity to alkanes was observed for pure supports.

The 15 wt $\%$ nickel loaded on $\gamma-\mathrm{Al}_{2} \mathrm{O}_{3}, \mathrm{SiO}_{2}, \mathrm{ZSM} 23$, and ZSM55 catalysts were also tested for HDO of 1-octanol (Table 5). As observed from the table, $\mathrm{C}_{8}$ hydrocarbons and DOE were primary products over highly acidic catalysts (15ZSM23 and 15ZSM55). ${ }^{31}$ On the other hand, $\mathrm{C}_{7}$ hydrocarbons and DOE were main products for $15 \mathrm{NiAl}$ and $15 \mathrm{NiSi}$. From these results it may be concluded that HDO of 1-octanol mainly proceeds through dehydration pathway in presence of acidic catalysts and dehydrogenation pathway for metallic catalysts.

3.3.6 Effects of WHSV. The effects of WHSV on conversion of 1-octanol and selectivity to products are shown in Table 6. As observed from table, 1-octanol conversion was decreasing with increasing WHSV. This is due to decrease of space time of reactants in the reactor. However, selectivity to products was persisted practically with increasing WHSV. Therefore, it may be concluded from these results that WHSV affects only conversion of 1-octanol without disturbing selectivity to products much.

\section{Conclusions}

The HDO of 1-octanol was investigated in a down-flow fixed-bed reactor using $\gamma-\mathrm{Al}_{2} \mathrm{O}_{3}, \mathrm{SiO}_{2}$, and HZSM-5 supported nickel catalysts prepared by incipient wetness impregnation method. The prepared catalysts together with pure supports were 
characterized by BET, XRD, UV-vis, TPR, TPD, and $\mathrm{H}_{2}$ chemisorption. The supported nickel (or nickel oxide) catalysts were observed to be associated with bulk nickel (or nickel oxide) as well beyond $10 \mathrm{wt} \%$ nickel loading on the supports. The strength and number of acid sites of the supported nickel catalysts were somewhat lesser compared to their respective pure supports. HDO of 1-octanol follows two different pathways depending on nature of the catalysts. HDO reaction proceeds largely through dehydration pathway over acidic catalysts with formation of DOE, isomers of octene, and $n$-octane as primary products. The dehydrogenation route becomes dominant over metallic catalysts leading to formation of 1-octanal, isomers of heptene, and $n$-heptane as predominating products. The higher conversion of 1-octanol and selectivity to alkanes was observed for hydrogen as a carrier gas compared to that of nitrogen. The conversion of 1-octanol was increased with increasing nickel loading on $\gamma-\mathrm{Al}_{2} \mathrm{O}_{3}$ and temperatures and decreasing pressure and WHSV. The combined selectivity to $n$-heptane, heptenes, and 1-octanal was increased with increasing nickel loading on $\gamma-\mathrm{Al}_{2} \mathrm{O}_{3}$ and temperatures and decreasing pressure. The combined selectivity to $n$-octane, octenes, and DOE was however observed to follow reverse trend.

\section{Nomenclatures}

$\begin{array}{ll}\text { HDO } & \text { Hydrodeoxygenation } \\ \text { WHSV } & \text { Weight hourly space velocity } \\ x \mathrm{NiAl} & x \mathrm{wt} \% \text { nickel supported on } \gamma-\mathrm{Al}_{2} \mathrm{O}_{3} \\ 15 \mathrm{NiSi} & 15 \mathrm{wt} \% \text { nickel supported on } \mathrm{SiO}_{2} \\ \text { ZSMy } & \mathrm{HZSM}-5 \text { with } \mathrm{Si} / \mathrm{Al}=y, \text { where } y=23 \text { and } 55 \\ \text { 15NiZSMy } & 15 \mathrm{wt} \% \text { nickel supported on HZSM-5 } \\ \text { TETD } & \text { Tetradecane } \\ \text { HEXD } & \text { Hexadecane } \\ \text { DOE } & \text { Di- } n \text {-octyl ether } \\ \text { OC } & \text { Octyl caprylate } \\ \text { OA } & \text { Octanoic acid } \\ \text { TOS } & \text { Time-on-stream }\end{array}$

\section{Acknowledgements}

The authors gratefully acknowledge the financial support from the Department of Science and Technology (DST), India.

\section{References}

1 Introduction to Chemicals from Biomass, ed. J. H. Clark and F. E. I. Deswarte, John Wiley and Sons, Ltd, 2008.

2 H. S. Choi, Y. S. Choi and H. C. Park, Renewable Energy, 2012, 42, 131-135.

3 D. Mohan, C. U. Pittman and P. H. Steele, Energy Fuels, 2006, 20, 848-889.

4 S. Fernando, S. Adhikari, C. Chandrapal and N. Murali, Energy Fuels, 2006, 20, 1727-1737.
5 G. W. Huber, S. Iborra and A. Corma, Chem Rev., 2006, 106, 4044-4098.

6 A. V. Bridgwater, Chem. Eng. J., 2003, 91, 87-102.

7 S. Czernik and A. V. Bridgwater, Energy Fuels, 2004, 12, 590598.

8 D. Hong, S. J. Miller, K. Agrawal and C. W. Jones, Chem. Commun., 2010, 46, 1038-1040.

9 E. Furimsky, Appl. Catal., A, 2000, 199, 147-190.

10 Q. Bua, H. Leia, A. H. Zacherb, L. Wanga, S. Rena, J. Lianga, Y. Weia, Y. Liua, J. Tanga, Q. Zhanga and R. Ruan, Bioresour. Technol., 2012, 124, 470-477.

11 H. Wang, J. Male and Y. Wang, ACS Catal., 2013, 3, 10471070.

12 M. Saidi, F. Samimi, D. Karimipourfard, T. Nimmanwudipong, B. C. Gates and M. R. Rahimpour, Energy Environ. Sci., 2014, 7, 103-129.

13 Y. Wang, J. Wu and S. Wang, RSC Adv., 2013, 3, 12635-12640. 14 B. Donnis, R. G. Egeberg, P. Blom and K. G. Knudsen, Top. Catal., 2009, 52, 229-240.

15 D. Procházková, P. Zámostný, M. Bejblová, L. Červený and J. Čejka, Appl. Catal. A: Gen., 2007, 332, 56-64.

16 M. R. D. Brimont, C. Dupont, A. Daudin, C. Geantet and P. Raybaud, J. Catal., 2012, 286, 153-164.

17 S. Sitthisa, T. Sooknoi, Y. Ma, P. B. Balbuena and D. E. Resasco, J. Catal., 2011, 277, 1-13.

18 S. Sitthisa and D. E. Resasco, Catal. Lett., 2011, 141, 784-791.

19 J. Huang, W. Long, P. K. Agrawal and C. W. Jones, J. Phys. Chem. C, 2009, 113, 16702-16710.

20 M. A. Alotaibi, E. F. Kozhevnikova and I. V. Kozhevnikov, Chem. Commun., 2012, 48, 7194-7196.

21 E.-M. Ryymin, M. L. Honkela, T.-R. Viljava and A. O. I. Krause, Appl. Catal., A, 2009, 358, 42-48.

22 O. Şenol, E.-M. Ryymin, T.-R. Viljava and A. O. I. Krause, J. Mol. Catal. A: Chem., 2007, 268, 1-8.

23 O. Şenol, T.-R. Viljava and A. O. I. Krause, Appl. Catal., A, 2007, 326, 236-244.

24 B. Peng, C. Zhao, I. Mejía-Centeno, G. A. Fuentes, A. Jentys and J. A. Lercher, Catal. Today, 2012, 183, 3-9.

25 V. Dhanala, S. K. Maity and D. Shee, RSC Adv., 2013, 3, 24521-24529.

26 G. Sadanandam, K. Ramya, D. B. Kishore, V. Durgakumari, M. Subrahmanyam and K. V. R. Chary, $R S C A d v$., 2014, 4, 32429-32437.

27 B. Scheffer, J. J. Heijeinga and J. A. Moulijn, J. Phys. Chem., 1987, 91, 4752-4759.

28 X. Zhang, R. Wang, X. Yang and F. Zhang, Microporous Mesoporous Mater., 2008, 116, 210-215.

29 A. Klerk, Ind. Eng. Chem. Res., 2005, 44, 3887-3893.

30 R. Bringué, M. Cadenas, C. Fité, M. Iborra and F. Cunill, Chem. Eng. J., 2012, 207-208, 226-234.

31 P. Kumar, S. R. Yenumala, S. K. Maity and D. Shee, Appl. Catal., A, 2014, 471, 28-38. 